\title{
Towards the Construction of Productive Interactions for Social Impact
}

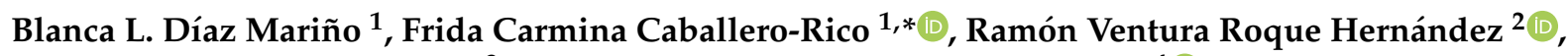 \\ José Alberto Ramírez de León ${ }^{3}$ and Daniel Alejandro González-Bandala ${ }^{4}$ (D) \\ 1 Center of Excellence, Autonomous University of Tamaulipas, Adolfo López Mateos University Center, \\ Victoria City CP 87149, Mexico; bldiaz@docentes.uat.edu.mx \\ 2 Faculty of Commerce, Administration and Social Sciences, Autonomous University of Tamaulipas, \\ Avenida Luis Echeverria, Infonavit Fundadores, Nuevo Laredo CP 88275, Mexico; rvhernandez@uat.edu.mx \\ 3 Academic Unit of Social Work and Sciences for Human Development, Autonomous University of Tamaulipas, \\ Adolfo López Mateos University Center, Victoria City CP 87149, Mexico; ramirez@docentes.uat.edu.mx \\ 4 Faculty of Commerce and Administration, Autonomous University of Tamaulipas, Adolfo López Mateos \\ University Center, Victoria City CP 87149, Mexico; danielgoba84@gmail.com \\ * Correspondence: fcaballer@uat.edu.mx
}

Citation: Díaz Mariño, B.L.; Caballero-Rico, F.C.; Roque Hernández, R.V.; Ramírez de León, J.A.; González-Bandala, D.A. Towards the Construction of Productive Interactions for Social Impact. Sustainability 2021, 13, 485. https:// doi.org/10.3390/su13020485

Received: 22 October 2020

Accepted: 30 December 2020

Published: 6 January 2021

Publisher's Note: MDPI stays neutral with regard to jurisdictional clai$\mathrm{ms}$ in published maps and institutional affiliations.

Copyright: (C) 2021 by the authors. Licensee MDPI, Basel, Switzerland. This article is an open access article distributed under the terms and conditions of the Creative Commons Attribution (CC BY) license (https:// creativecommons.org/licenses/by/ $4.0 /)$.
Abstract: Understanding the value of research for society has become a priority, and several methodologies have been developed to assess the social impact of research. This study aimed to determine how productive interactions are developed during the execution of research projects. A retrospective study was conducted on 33 projects from 1999 to 2020. Semi-structured interviews with the technical managers were conducted to analyze how different actors of the project-researchers, government officials, and civil society and private sector stakeholders-were involved, illustrating how productive interactions occur in specific biodiversity contexts. The results revealed different levels and intensities of productive interactions; on the one hand, three projects involved all actors; eight involved researchers outside the institution; and 25 involved community members. The number of participants ranged from 2 to 37. All research evaluated had a disciplinary orientation. The type and time of interactions with other interested parties depended on the amount of funding, project type, project duration, and, significantly, on the profile of the technical manager. The importance of assessing and valuing productive interactions was identified as a fundamental element in promoting the social impact of research, as well as integrating inter- or multidisciplinary projects that impact the conservation of socio-ecological systems.

Keywords: productive interactions; social impact; case study; exchange knowledge

\section{Introduction}

Funding agencies, governments, and the community in general have been increasingly interested in understanding the impact and contribution of research on economic and social development [1,2]. Since 2014, the United Kingdom has been conducting the largest assessment of the impact of academic research ever undertaken, in order to allocate funds to projects that meet the criteria set out in the Research Excellence Framework (REF) $[3,4]$. Initially, the impact of the research was considered based on direct economic effects, such as the income generated by licenses, patents, and spin-out companies. International agencies such as the Organization for Economic Cooperation and Development (OECD), the World Bank (WB), and, in the case of Latin America, the Latin American and InterAmerican Network on Science and Technology Indicators (Red de Indicadores de Ciencia y Tecnología-RICYT) have been leading the implementation of this effort [5]. Another traditionally used approach is assessing the number of publications in highly-ranked journals, and the citations they receive. In this approach, the notion that researchers produce decontextualized, neutral theoretical knowledge that flows linearly to the general population is maintained [6]. 
Based on the premise that science is important for society in general, the approaches used for its assessment have been modified. There are arguments that indicate that it is not feasible to have a standardized method to assess research impact. Some purport that having several methodologies to assess the social impact of research is of benefit [7].

The social impact of research has been considered since the 1990s (1) as a product, by which knowledge with potential social value is incorporated into the form of information, products, tools and instruments, methods, and models; (2) as knowledge use, by which processes of interaction between researchers and interested parties can yield the adoption of knowledge by interested parties; and (3) as social benefits arising from the use of research results in different areas [8].

Several proposals have stated that it is important to first clarify what is understood by the term "research impact", because the concept is also used to describe four stages of the process: (1) Creation of a knowledge product, a stage at which researchers are considered experts that generate an academic product such as an article or lecture; (2) awareness of findings, which occurs when researchers are approached by the media to learn about and disseminate the results through social networks, print media, television, and radio; (3) use of the knowledge product, which occurs when someone from outside the academic realm adopts the research idea; and (4) social benefits through which "an effect, change, or benefit for the economy, society, culture, public policies or services, health, environment, or quality of life, beyond academia" [8] (p. 217) is produced. These proposals indicate that, although the first three stages are necessary, they are insufficient to achieve social benefits [8,9].

In this sense, the relational commitment approach proposed to assess the research process ranges from the creation, awareness, and use of knowledge to its social impact. It argues that long-lasting interactions between academics and other actors generate knowledge products that are likely to have a positive social change. A process in which researchers must work directly with other actors to balance rigor with relevance, by including the interests, opinions, and ideas of the end users, is considered optimal [1].

The social impact of research is the result of a complex, indirect, and multidirectional system, which makes it difficult to associate a particular social impact with a specific research effort. Other reasons for this include the time lag between the generation of research results and the achievement of social benefits [10-12]. When the project is assessed before or once completed, the impact may not yet have occurred, and when this assessment is conducted much later, other parties may not remember exactly how the project progressed [11]. On the other hand, the research development and his interactions are in a process of permanent change, this as a result the activities done, the new-found results, and the ad of new visions. This takes us on the investigation process-consciously or unconsciously to build and rebuilt to obtain the planned result [12].

The relevance of discussing contributions rather than attribution is considered because research is only one influencing factor that supports the results [11,13-15]. The different meanings that the "social benefits of research" have for the various actors-higher education institutions, funding agencies, and government bodies-deriving from their own perspectives, views, and interests, represent another difficulty when assessing the impact of research [11], in addition to the segmentation of public policies and the need to establish a more comprehensive evaluative approach $[16,17]$. In this context, productive interactions are an alternative approach that attempts to minimize the difficulties that occur when assessing research impact [12].

The idea behind the concept of productive interactions is that academic knowledge cannot simply be delivered; it develops through the interaction with interested parties in a particular context, and that impact is the result of a collaborative contribution. Therefore, the construction depends on researchers and interested parties [18].

A productive interaction is defined as any exchange among researchers and interested parties where robust and socially relevant knowledge is produced and valued [12]. An interaction is considered productive when it leads to efforts of the interested parties to use research results, experiences or practical information [12]. 
The interactions can be direct, indirect, or financial, and they are considered a necessary but not sufficient step for research to be valued through generating a positive impact in specific social contexts [12]. The interactions must be interpreted according to the context in which the impact occurs $[8,17,19,20]$.

The implementation of this approach has focused on measuring interactions, undermining its fundamental purpose because determining social impact is not limited to counting interactions [17-21]. If research can have an impact on society, it results from the type and intensity of the interactions between a research group and the interested parties [9-19]. This interaction may begin at different times throughout the research process, such as when the research agenda is defined, during the research itself, or when the results are communicated to the interested parties. Therefore, it should be recognized that it may not be a simple process, because interactions with other actors-funding agencies, students, collaborators, community-are common in science and generally part of researchers' work, while the exchange of ideas and opinions between academics and professionals from the public, social, and private sectors is less common [4]. It is fundamental to identify the actors with whom interactions are carried out to determine the potential for impact, design strategies for the co-production of knowledge, and skill development to generate productive interactions [4].

In this context, the concept of social capital is an element considered present in the construction of productive interactions, in which trust is the basis for creating standards of reciprocity, networks, modes of civil participation, and both formal and informal rules and institutions [22]. The different aspects of the context in which individuals interact affect how they learn, develop, and interact. Individual behavior is strongly affected by the context in which interactions occur, and is not merely the result of individual preferences [23].

Studies conducted at the group (productive interactions to exchange knowledge in healthcare building design) [24], individual (creating research impacts through the productive interactions of an individual: An example from South African research on maritime piracy) [15], or organizational (experience in R\&D collaborations, innovative performance, and the moderating effect of different dimensions of absorptive capacity) levels provide evidence of the role of interactions beyond the scope of the social impact of research [25]. In this sense, the study conducted on the growth of knowledge in university-industry innovation networks establishes the importance of innovation networks between science and technology and agents of the industry or other fields, by integrating experts from various fields. The growth of knowledge in these networks does not occur automatically, because it depends on factors such as the density of knowledge and the actors involved, as well as their preparation [26].

The objective of this study was to determine the social impact of research by studying the productive interactions between science and society [12]. This approach prioritizes interactions between research and its interested parties, which are termed "productive interactions". It applies to the field of ecology and biodiversity conservation, but also includes exercises conducted in the social sciences, humanities, artificial intelligence, and biomedical sciences $[10,27,28]$. This is the first study of this type to be carried out in Mexico and establishes a baseline for future studies.

The next section outlines the methods, data, and case selection. The context of the analyzed cases is subsequently described. Then, the following section presents the interactions between the interested parties. Finally, the value of the productive interactions approach for assessing the social impact of research is discussed.

\section{Conceptual Background}

Analyzing productive interactions as an alternative to determining the social impact of research focuses on developing the process of knowledge production and the role played by those involved in this process [12]. Three types of "productive interactions" indicate how researchers communicate with their environments, which can be established during different moments, such as before, during, at the end of, or after the project [12]: 
- Direct interactions: "Personal" interactions that involve direct contact between people; interactions that are based on face-to-face meetings or telephone calls, emails, or videoconferences.

- Indirect interactions: Contact established through some type of material or "medium"; for example, scientific articles, books, project data, and exhibitions.

- Financial interactions: When potential interested parties participate in an economic exchange with researchers, such as a research contract, financial contribution, or "cash" contribution to a specific research program. These occur in the context of direct or indirect interactions [12].

In this process, the traditional hierarchical institutional structures that determine the activities from the top of the organizations are transformed into a horizontal interactive process in which the interested parties interact, and any of the three types of interactions can become productive $[12,28]$. The interactions that should be interpreted are identified considering the contexts and fields of knowledge in which the impact emerges; understanding these elements can solve attribution problems $[8,29,30]$.

Previous studies have demonstrated that, when communication occurs "face-to-face", the participants assess facial expressions, body language, and vocal tone to determine the reliability, reputation, and knowledge of the history of the other participants, which may not be known prior to the interaction. These increase (or decrease) the likelihood of cooperation and the processes by which individuals build trust with others through reciprocal behaviors [12].

The productive interactions of research with interested parties are considered vital for achieving social impact, and can be managed strategically to ensure endless reproducibility [12]. The results of the study on the interactions of Dr. $Z$ with the other interested parties demonstrated that the richness of the interactions derives from the narrative of the interviews coupled with other external validations, and not from counting them [15]. Therefore, the mapping of productive interactions should consider the complexity of the research dynamics [17].

Research becomes impactful when the interested parties or actors (in research, the public sector, civil society, or entrepreneurial arenas) positively modify attitudes, opinions, and behavior as a result of research.

The objective of this study was to understand how productive interactions are managed between actors from academia, society, the public sector, and the business sector, to then outline their social impact.

The questions raised in this study are:

1. What interactions do the researchers create and describe with other stakeholders?

2. How can we evaluate the results and social impacts?

\section{Materials and Methods}

This study evaluated research projects conducted from 1991 to March 2020. The research method had four stages (see Figure 1). The first was the search, identification, and collection of research projects that became case studies. The second stage comprised information gathering, and an instrument was designed and validated based on the Social Impact Assessment Methods (SIAMPI) methodology developed by [12].

SIAMPI offers an approach for social impact assessment based on concrete data about the key elements in the production of social impact: Productive interactions and stakeholders. In research assessment, according to SIAMPI, social impacts are identified and assessed by tracking productive interactions. Compared to other methods for evaluating social impacts, the emphasis is on processes that induce impact, rather than the impacts itself. As a consequence, the results of impact assessments can be linked more easily to concrete research activities (projects, programs, and institutes) and are timelier in relation to policy processes. 


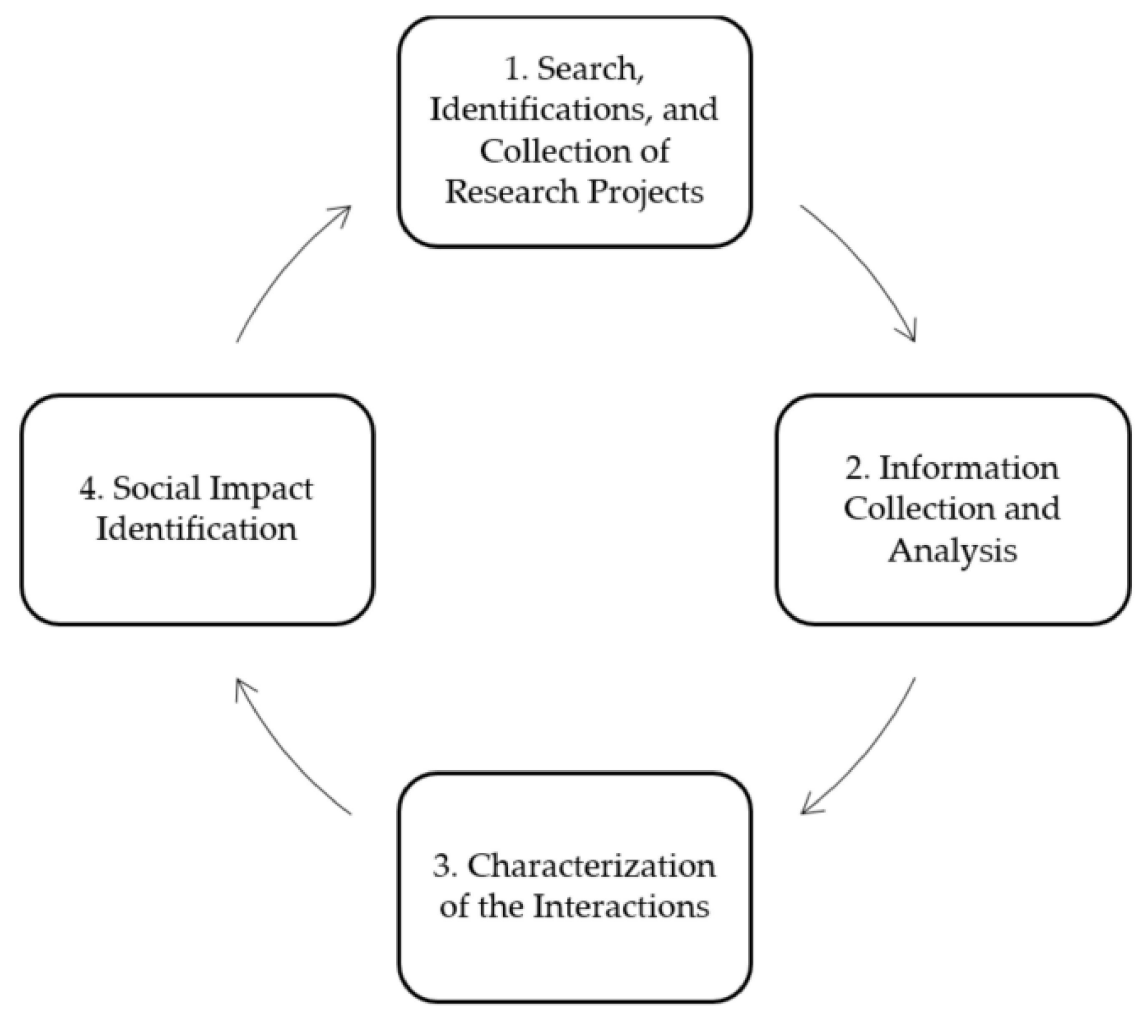

Figure 1. Methodology flow.

A questionnaire was developed to conduct semi-structured interviews for evaluations of social impact. The instrument had seven questions structured according to the conceptual framework of productive interactions. The questions raised in this study were:

1. Which interested parties collaborated during project development?

2. What type of interactions were established?

3. When did the interaction start?

4. What was the purpose of the interactions with the other interested parties?

5. How does one describe the interactions with the other interested parties?

6. Which results and impacts of the project have been directly relevant, for which interested parties, and why?

7. To what extent have the research projects produced sustainable results?

Data collection was performed through semi-structured interviews with technical managers of the selected projects. Individual interview protocols were established for each technical project manager. Each technical manager noted and described the interactions with each of the participating stakeholders. Records of each interview were kept. Complete transcripts of the interviews were made, subsequently coded for each actor of the quadruple helix, and then concentrated in an Excel base for analysis, in some cases, the Sankey Diagram Generator (http:/ / sankey-diagram-generator.acquireprocure.com) was used.

A pilot test was applied to three researchers and adjustments were made based on their observations, mainly associated with direct, face-to-face interviews and the time required to complete the interview (approximately two and a half hours). The interviews with the technical managers were arranged by appointment, upon agreement with each researcher, and conducted in a private place at the workplace of each researcher. All interviews were conducted by the same person to ensure criteria consistency.

In the third stage the characterization of the interactions was performed. The context and the impacts of each project were also analyzed. The networks of the involved actors were reconstructed from this information. The forms of interaction developed during the research process were also configured. Afterwards, we identified the impacts. 
Finally, in the fourth stage, possible social impacts by project under study were identified, and the directions of future studies were outlined.

\section{Results}

\subsection{Search, Identification, and Collection of Research Projects}

Projects developed in the Protected Natural Areas of the Tamaulipas by researchers from the Autonomous University of Tamaulipas (Universidad Autónoma de TamaulipasUAT) were identified. The search was carried out using the databases of the UAT, the Mixed Funds (FOMIX) of the National Council on Science and Technology (Consejo Nacional de Ciencia y Tecnología-Conacyt), the Tamaulipas Council on Science and Technology (Consejo Tamaulipeco de Ciencia y Tecnología-Cotacyt), the Ministry of Public Education-Professional Development Programs for Teachers (Secretaría de Educación Pública — Programas para el Desarrollo Profesional-SEP-Prodep), the Commission for the Knowledge and Use of Biodiversity (Comisión Nacional de Biodiversidad-Conabio), and the National Commission for Protected Natural Areas (Comisión Nacional de Áreas Naturales Protegidas-Conanp). In total, 65 relevant projects were identified. Upon review, 32 were discarded as they were not research projects. This study considered 33 projects that were conducted from 1999 to March 2020. From these, 18 researchers were identified as technical managers.

\subsubsection{Context of the Projects}

The projects were developed by researchers from four units of the UAT, namely, the Institute of Applied Ecology (Instituto de Ecología Aplicada-IEA), the Multidisciplinary Academic Unit Reynosa-Aztlán (Unidad Académica Multidisciplinaria Reynosa-AztlánUAMRA), the Faculty of Veterinary Medicine and Zootechnics (Facultad de Medicina Veterinaria y Zootecnia-FMVZ), and the Faculty of Engineering and Sciences (Facultad de Ingeniería y Ciencias-FIC). Figure 2 shows the Projects and Areas, the Protected Natural Areas (PNA), and the Higher Education Units (HEU) that were involved.

\subsubsection{Project Management}

Most of the projects were conducted in the Laguna Madre and Delta del Río Bravo (16) and in the El Cielo Biosphere Reserve (13). The topics addressed in the projects are diverse (13), with a study of fishing resources being notable (8). The projects have been mainly developed in the IEA.

We identified 18 technical managers responsible for executing 33 research projects, with the following distribution:

- All of them hold doctoral degrees and full-time professor appointments, except for one person.

- A total of $61.11 \%$ belong to the CONACYT National System of Researchers (Sistema Nacional de Investigadores-SNI).

- A total of $94.4 \%$ are male.

- The areas of specialization are: Aquaculture (2), Birds, Botany, Plant Physiology, Hydrology, Genetic Diversity, Natural Resource Management, Integrated Pest Management, Phylogenetics, Animal Biology and Zoology, Ethnobiology, Forest Ecology, Aquatic Systems, Ecology and Aquatic Resource Management, Bacterial Microbiology, Bioremediation, and Food Science and Technology. 


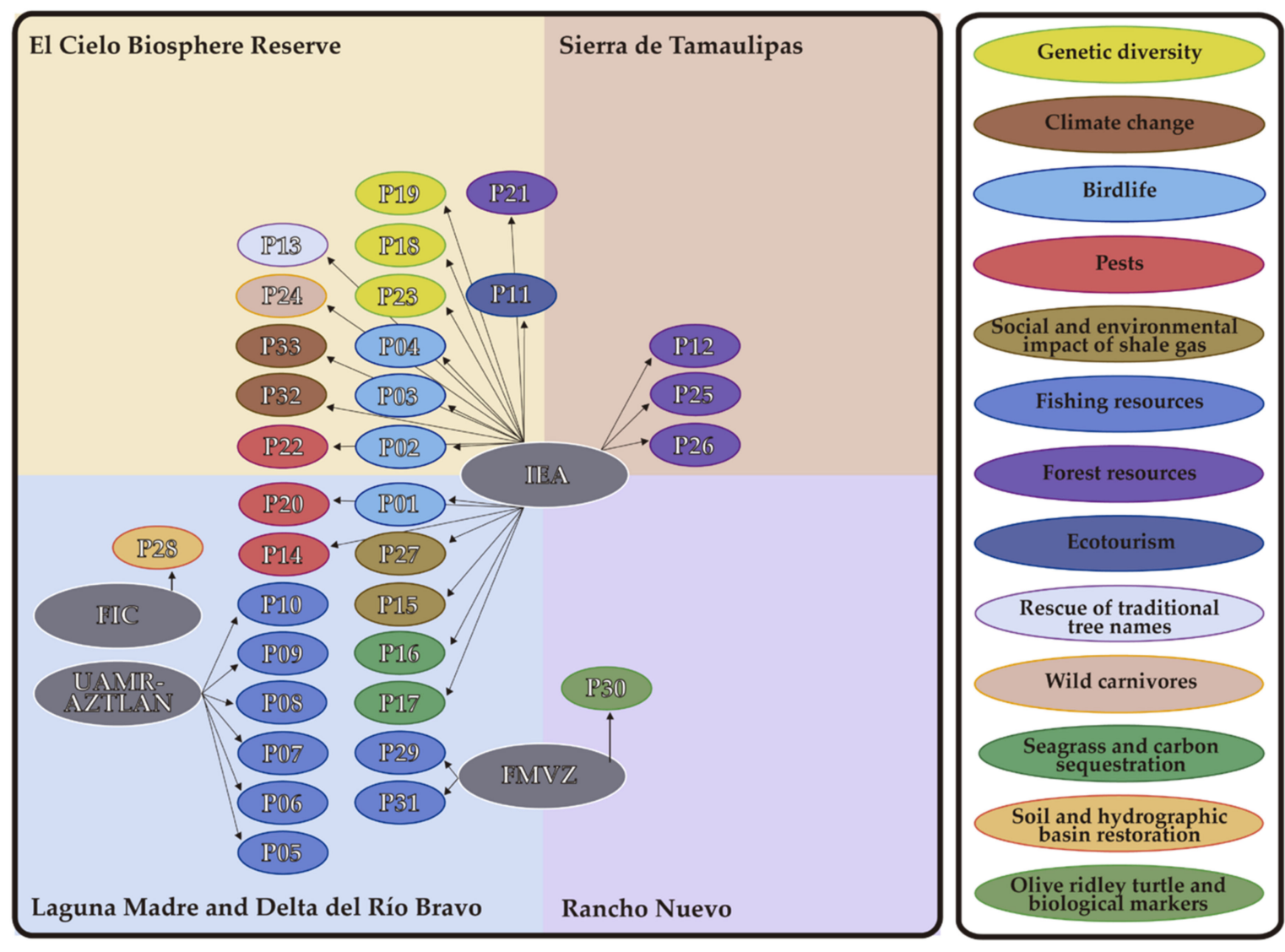

Figure 2. Projects and areas, Protected Natural Areas (PNA), and the Higher Education Units (HEU) involved.

\subsection{What Interactions Do the Researchers Create and Describe with Other Stakeholders?}

The research projects involved 375 participants: $68.00 \%$ (255) from the research sector, $20.53 \%$ (77) from civil society, $10.40 \%$ (39) from the public sector, and $1.07 \%$ (4) from the business sector. The characterization of the participating groups of the analyzed projects is presented in Table 1.

Table 1. Characteristics of the actors.

\begin{tabular}{|c|c|c|c|}
\hline Research & Public Sector & Civil Society & Business Sector \\
\hline $\begin{array}{l}\text { Researchers and students from the } \\
\text { same institution. Participated } \\
\text { throughout the entire project as } \\
\text { associated researchers with specific } \\
\text { responsibilities for data collection, } \\
\text { laboratory work, species } \\
\text { registration, statistical analysis, } \\
\text { article writing, presentation } \\
\text { preparation, seminar organization, } \\
\text { book elaboration, and technical and } \\
\text { administrative report elaboration. }\end{array}$ & $\begin{array}{l}\text { Primarily comprised of } \\
\text { funding agencies with which } \\
\text { a mostly administrative } \\
\text { relationship was maintained } \\
\text { to meet established deadlines } \\
\text { and ensure the delivery of the } \\
\text { agreed-upon academic } \\
\text { products. }\end{array}$ & $\begin{array}{l}\text { Members of the } \\
\text { communities in which the } \\
\text { projects were developed, } \\
\text { and three formally } \\
\text { constituted civil } \\
\text { organizations. }\end{array}$ & $\begin{array}{l}\text { Small companies, and } \\
\text { mainly located in the } \\
\text { territory where the project } \\
\text { was developed. Involved } \\
\text { from the beginning of the } \\
\text { project because the calls for } \\
\text { public funding required it. }\end{array}$ \\
\hline
\end{tabular}

The methodology described by the technical staff that are responsible for the integration of the working groups states that "We invite our research group colleagues from both inside and outside the institution because a project is more likely to be funded if there is a solid research group that can generate joint publications" IP13.

It should be noted that $87.50 \%$ of the researchers, technical staff, and thesis students who participated belonged to the same entity as the technical manager, and participated in 
more than one project. Figure 3 depicts the relationships between the projects and the four different sectors.

Diversity and impact of climate change on vascular epiphytes, in...

Impact of climate change on low-status vascular epiphytes bajo...

Population variability of penaeid shrimp in the estuarine...

Assessment of the health status of olive ridley turtles through...

Population structure, health, and heavy metals of the shrimp...

Bioremediation of hydrocarbon-contaminated soils by the...

Restoration of the hydrographic basin of Laguna Madre.

Study applied in detail in mountain ecosystems of the eastern...

Sierra de Tamaulipas, its natural resources, and prospects for...

The wild carnivores of El Cielo Biosphere Reserve: population...

Exploration of genetic diversity in native breeds and perspectives...

Diversity of fruit flies (Diptera: Tephritidae) associated with...

Phytosanitary diagnosis of pine-oak forests in mountainous... Monitoring for early detection of cactus moth in the Laguna Madre...

Management and conservation of the germplasm of three species..

Analysis of genetic diversity and biotechnological potential dof the...

Monitoring of seagrasses and salinity in Laguna Madre de Tamaulipas.

Spatial distribution, structure, and content of content in submerged..

Study for the qualitative identification of potentials environmental..

Strengthening the monitoring of cactus moth in the APFF Laguna.

Rescue of the traditional nomenclature for wild trees in El Cielo..

Ecology, conservation, and sustainable management of natural

Strategies for the development of the ecotourism potential in El..

Validation of a sustainable capture system for the crab fishery in..

Preparation of a map of productive zones for Blue Crab.

Development and transfer of processes for the commercial...

Innovation, development and technology transfer of new fishery...

Development of new fish products (Mugil cephalus (linneo, 1758) Lisa.

Development of fish by-products.

Community participation for the Conservationof the Green Macaw...

Identification of priority conservation areas for the green macaw...

El Cielo bird monitoring program.

Birds of the Laguna Madre in Tamaulipas.

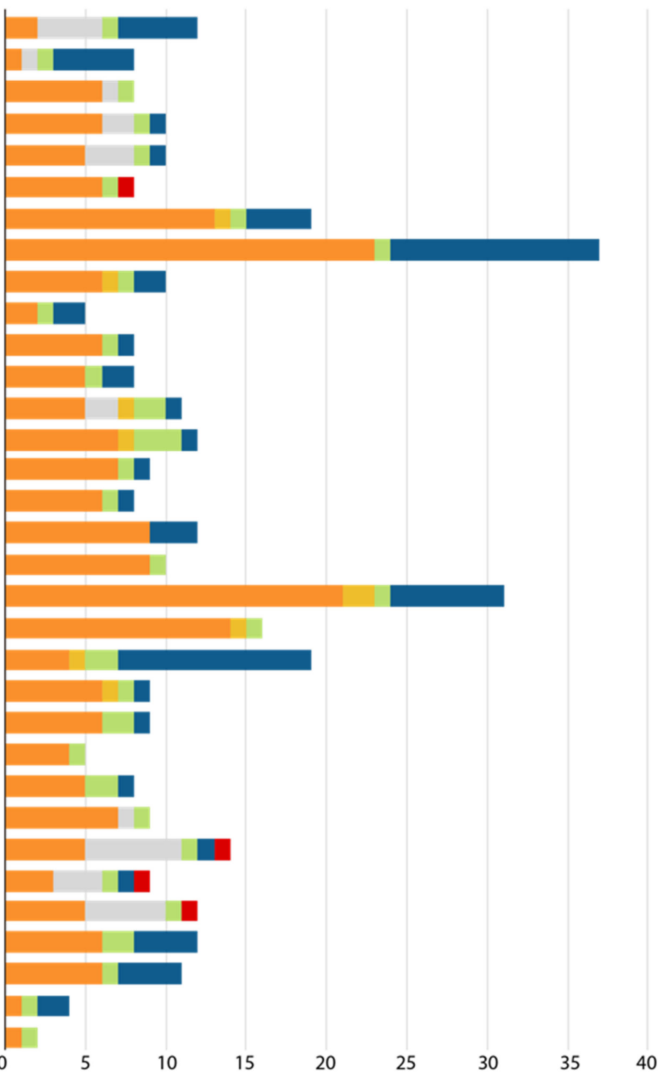

Research Thesis students Technicians $\square$ Public Sector $\square$ Civil Sector $\square$ Business Sector

Figure 3. Relationships between projects and the four sectors.

The technical managers who were interviewed stated that they used the three types of interaction to establish contact with the participants-direct, indirect, or financial. The most frequent were direct interactions $(64.78 \%)$. They particularly mentioned face-to-face meetings, email, and scientific articles (Figure 4).

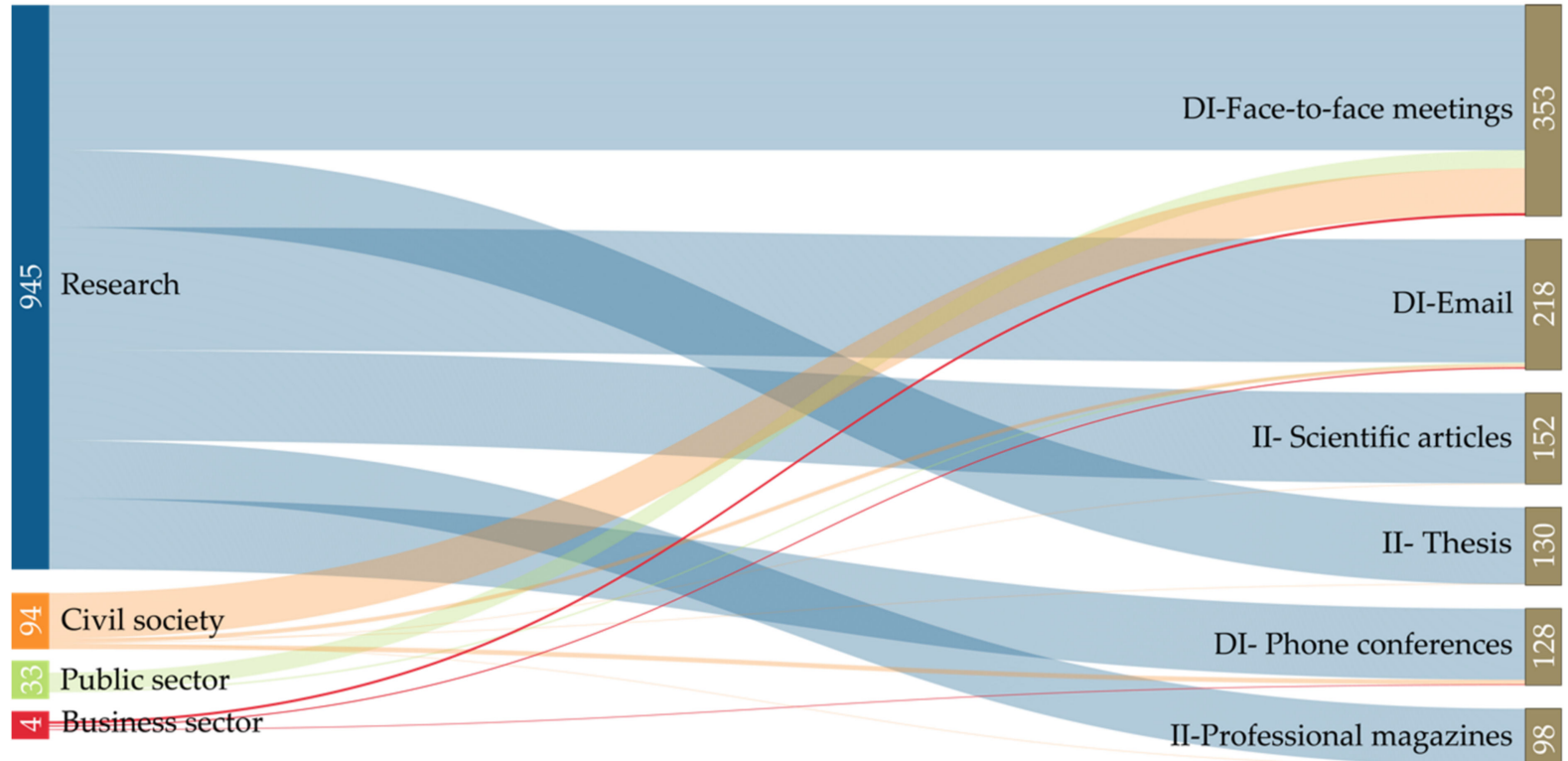

Figure 4. Types of interactions with the interested parties. 
The integration of the participants in the research projects occurred at different stages of the process, and $69.60 \%$ were invited to participate before the project started (Figure 5).

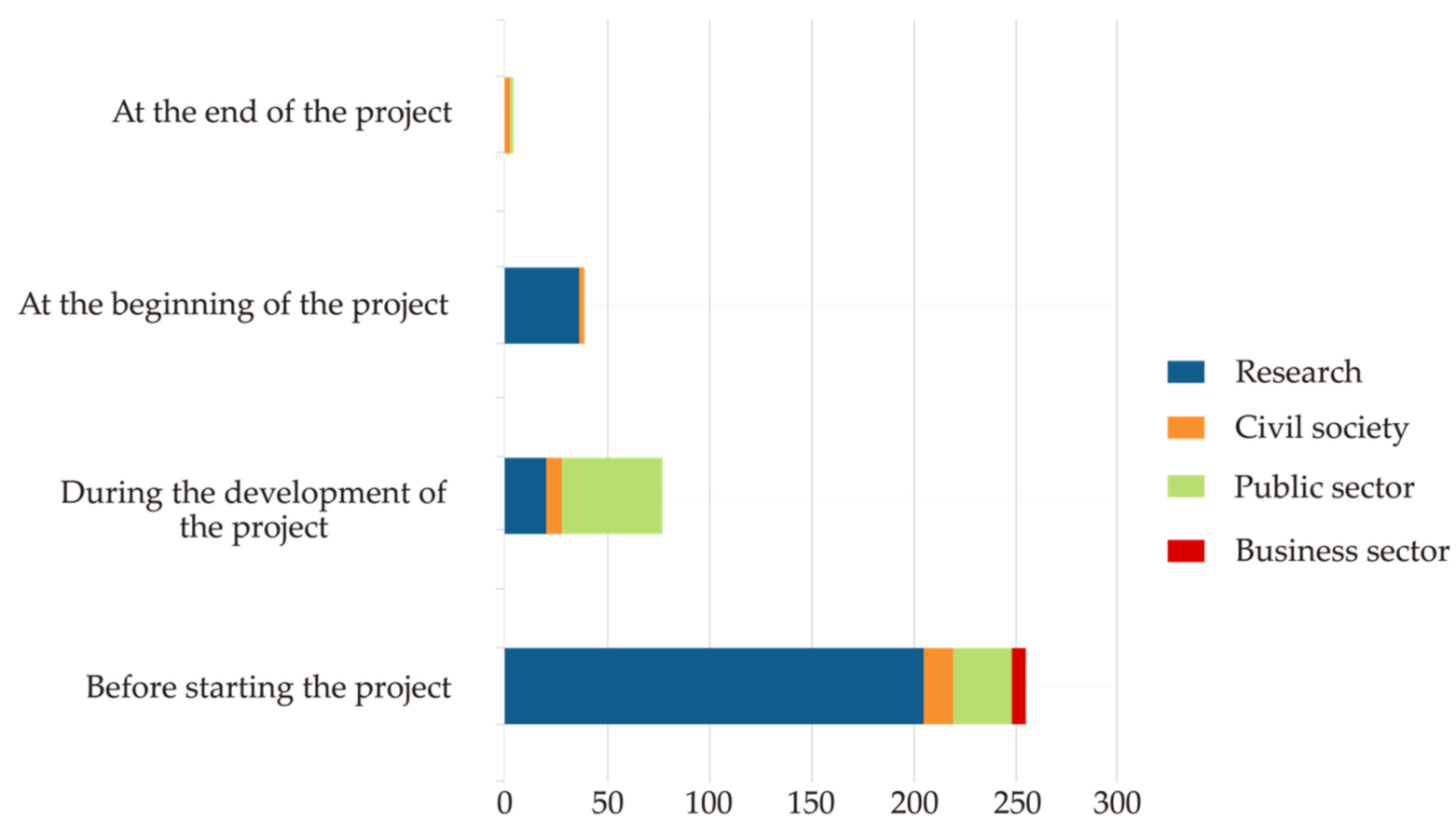

Figure 5. Stage of integration of the interested parties in the project.

Of all interactions, $80.59 \%$ were carried out in an institutional manner, either as part of the team defined in the project or through a signed collaboration agreement. For civil society, the relationship with $90.91 \%$ of the participants was informal and composed of community members who joined the project.

The frequency of interactions between participants varied depending on the type of work or collaboration. In total, $47.34 \%$ maintained permanent contact. The fact that the interactions with the government were sporadic stands out.

The technical managers who were interviewed noted that the purpose of the participation of other actors $(67.59 \%)$ was mainly to enhance the knowledge required for project development, perform collaborative work, and obtain specialized knowledge. It is important to note that a participant may join the project for more than one purpose (Figure 6).

Regarding funding of the projects, this mostly came from the federal and state public sector 96.97\%, (Conanp, Conabio, Fomix-Tamaulipas, Conacyt, UAT, SEP-Prodep); 3.03\% came from civil society.

Technical managers described and reported the reasons for inviting other actors to collaborate on the project, which are presented by project and researcher below. The IP identifier followed by a number represents information on each project that was provided for us during the interviews.

Researchers: "The relationship with our research colleagues was based on the individual contribution of each one of them, according to their knowledge and professional profile to meet the established objectives" IP29. "The projects have also been proposed by the research colleagues because magnolia (Magnoliácea) has a biotechnological potential that other researchers are already researching. In addition to this, I have a doctoral thesis that gave continuity to other objectives that were not included in the funded project" IP18.

IP1, IP2, IP3, and IP4 agreed that thesis students are important because they conduct field work, data analysis, literature reviews, and they can publish with the students, giving continuity to other objectives that were not included in the funded project.

"Teaching and training is provided to young researchers and thesis students" IP17. "With the students, the interaction was formative and collaborative in both field and 
laboratory work" IP29. "In the courses given to schools or community inhabitants, the thesis students participate with different didactic activities" IP32 and IP33.

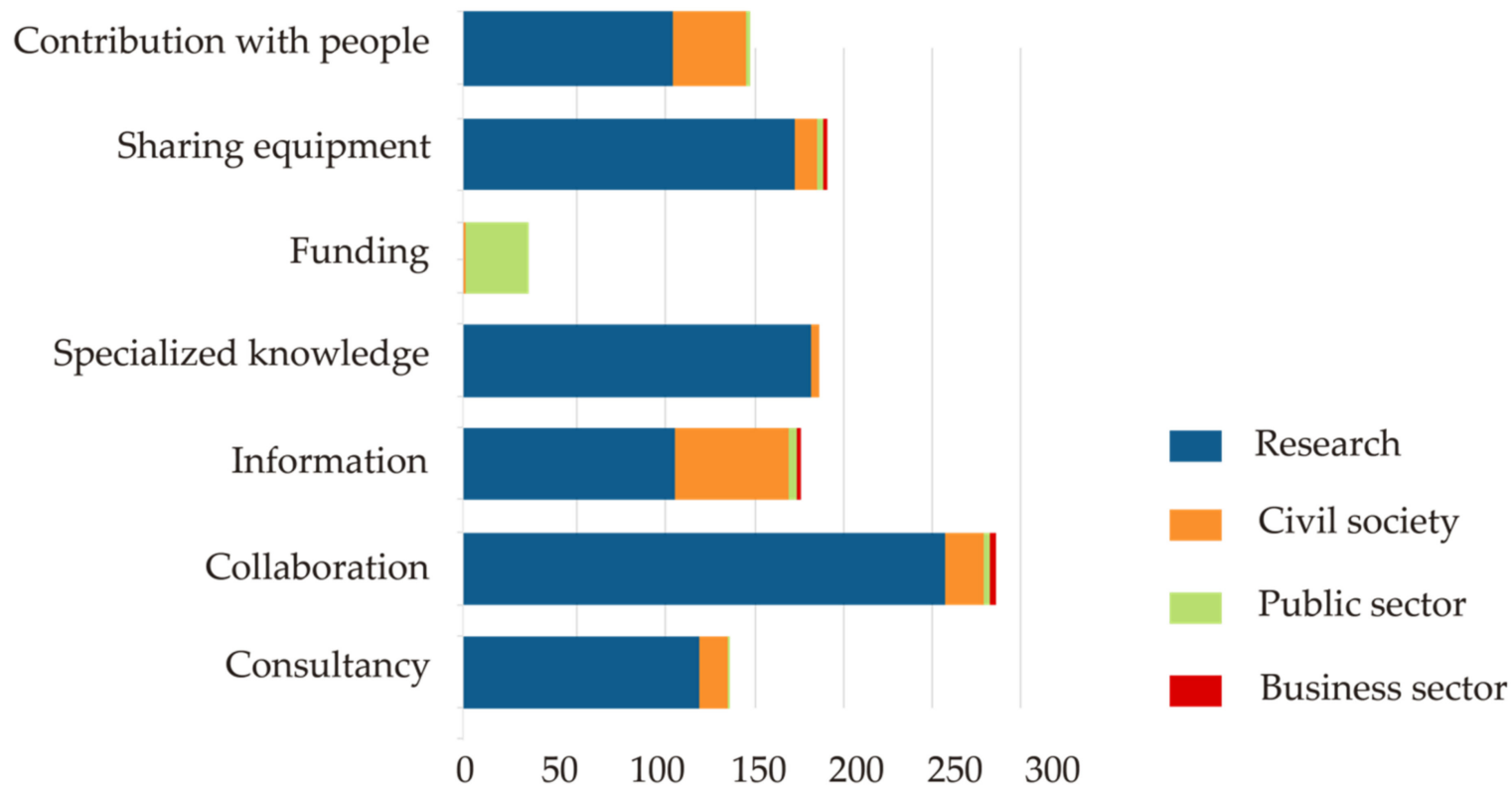

Figure 6. Reasons for the integration of interested parties in the project.

Government sector: The main interaction with this sector was to obtain funding and information or regulations for compliance with technical, administrative, and academic commitments established in the project IP 1-32.

Only a technical manager indicated that "I submit the articles that I publish or the book that I prepare in a formal manner; officially I do not know what they do with that information. I suppose they use it because they call me later to discuss some issues or related matters" IP22.

Civil society: "We have a very close relationship with the members, and some of us have maintained these for almost 20 years" IP1, 2, 3, and 4. "Visits and interviews were conducted with local communities to obtain and exchange information, in addition to promoting the project" IP12. "It was important to establish communication with local communities, since part of the impacts also affect human beings. For this, field visits were carried out to know the views of the rural inhabitants, and thus assess the environmental impacts" IP15. "The relationship with the inhabitants of Alta Cima was always friendly and respectful" IP19.

"The relationship with the community members was good" IP23, IP24, IP26, and IP32. "Direct, informal interactions and interviews to obtain information" IP25. "There was a friendly relationship with the inhabitants of the reserve. We were in contact with the community since the beginning of the project to notify them about the activities that we were going to carry out" IP33 and IP26.

"They were paid for their services" IP23 and IP26. "The relationship with the fishermen was limited to an employment agreement" IP31.

The main purpose of the interactions is: "They have taught us many things about birds, and they have learned from us, for example, the scientific names of birds" IP1, IP2, IP3, and IP4. "We interacted with the community inhabitants; they have expert knowledge about the pasture, and there is an implicit and explicit knowledge exchange and transfer" IP17. "A great exchange of information on practices regarding the use of palm occurred, and they showed interest in improving its use" IP19 and IP24.

"The relationship with the fishermen was based on the support of their knowledge in the field and with other fishermen, so that the field work was facilitated for us. Interaction between my colleagues with the fishermen was limited, since I was the one who interacted more with them" IP29. 
"The relationship with the inhabitants of Rancho Nuevo was informal; we learned from their experience in the area information on the management of turtles, and on how to properly hold and measure the olive ridley turtle" IP30.

They participated in the projects developing various activities such as: "The fishermen of the Laguna Madre area participated in the testing and validation of the ecological traps" IP10. "The traps were placed in areas related to the possibility of better fishing, the proximity to the area where the fisherman lives, and in areas that are not very busy, so there is overexploitation in some zones. The fishermen commented that they move the traps according to where they consider the animals will be, so there was a second visit to the entire selected area, and a new cartographic map defining the georeferenced location of the area of interest was developed" IP9.

"The local society was invited to participate in monitoring the cactus moth, and training courses and workshops were held for future contingency practices" IP14, IP20. "The community members participated in restoration activities" IP27.

"During the year that the project lasted, some people participated as field guides and were interested in understanding the activities and results of the project" IP32.

"We trained them in various activities related to the project, the environment, and the conservation of biodiversity". "Training community guides in macaw watching and counting through workshops and courses". "Training of six internationally recognized community guides" IP1, IP2, IP3, and IP4. "The community was taught through workshops in the center and north of Laguna Madre, and in the south, on reforestation. Knowledge transfer was carried out" IP16.

"At the end, we gave a lecture to individuals from Conanp and community members on the findings of the sampling and the biomedical and blood values, which were the first for this endangered turtle" IP30.

"An environmental education program was started as the community did not understand that they (the birds) were lined up first to be released later, and they needed to be educated on conservation" IP2. "Environmental education workshops were run for children in the community using a booklet, which was developed for children to understand the importance of the conservation of the green macaw" IP3.

"A course on Ecology and Conservation of Epiphytes was taught in two primary schools in the reserve to inform on the results of the project" IP33. "Our contribution was to provide environmental education, and they learned" IP24.

As a result of productive interactions, community members have been able to learn. "This raises awareness for conservation" IP17. "They gave more importance to the conservation of the species because they were not aware before that it was endemic, and that it does not exist in any other region of the world, which gives more value to conservation. They were interested in the results of the studies to carry out management and conservation practices, as they see great potential in it, which should result in the establishment of a joint management plan" IP18.

The contribution was very positive because we helped them improve their harvesting technique, emphasizing the importance of leaving fruits so that the population does not decrease, as well as identifying pests in the palm leaves and explaining them how to choose the best product. In the end, ideas for future projects emerged, namely the formation and establishment of a management unit for the conservation and sustainable use of wildlife (UMA) because, as it is within the reserve, it is limited only to the collection of leaves and not to the sale of plants" IP19.

"The importance of forest inventories was transmitted to producers for better forest management" IP21. "Some people participated as field guides and were interested in understanding the activities and results of the project in order to later share this knowledge with tourists in the reserve" IP32.

"However, they realized that the institutions do not implement corresponding sanctions and/or punishments" IP3, IP4. 
Business sector: "The experience I had with the businessman was very good because he knew the area very well and had a clear vision of what he wanted, and it was possible to work with his team. For the development of the products, they worked in close collaboration with the participating companies, receiving constant feedback. The results allowed him to obtain other equipment and, through the IDEAS program, Conacyt could hire thesis students for his company [...] he was kidnapped as a result of the insecurity in the area [...] then he died" IP5, IP6, IP7, and IP8. "My relationship with the businessman was only to request information" IP28.

\subsection{How Can We Evaluate the Results and Social Impacts?}

The empirical analysis of 33 projects addressed as case studies supported the characterization of different types of knowledge and research orientations, different types of interactions, diverse beneficiaries, and the diversity of mechanisms and conditions that promote contributions to social impact that are recognized as corresponding to a given context $[8,19,29]$. It allowed us to identify four groups of projects.

The first group was made up of 17 projects that addressed a topic for a single occasion. Although interactions with other stakeholders were reported, the reflection was on what their potential impact would be. The main beneficiaries would be the members of the research group by strengthening their research capacities, the production of scientific articles, training of human resources, and knowledge of the territory.

The second group was composed of six projects with continuity in at least two periods and associated with a specific area. This group was made up of researchers working at the UAT for five years or less, which is why it was assumed that they were in the process of development.

The third group was made up of six projects on fisheries resources developed from 2004 to 2014 in the same area, the Laguna Madre and Delta del Río Bravo, and comprising different phases of basic and applied research, technological development, and innovation. Its members have the highest certifications as researchers. They participate in national evaluation committees and are part of national and international networks. This group has been reshaped and applies the same work model called "from research to innovation" in its new projects.

The fourth group was made up of six projects developed from 1999 to date, aimed at avifauna. The conformation of the projects and the associated work group presented characteristics that allow us to indicate that it is a consolidated group that has successfully linked its projects to the association and transfer of knowledge with the community. This generated a model called "from research to citizen science".

The projects documents and information collected in the interviews with the technical managers were reviewed, it was found that the analyzed investigation projects are approached from the Model 1 perspective, focuses on the traditional role of university research in an elderly linear model of innovation [31]. This reflects a basic university research, interested in the finding of basic principles, oriented by disciplinary research structure, controlled by peer disciplinary, exercised process that performs in a highly hierarchical organization [32] "is not concerned with the application, diffusion and use of knowledge, and Mode 1 does not focus on features in relation to problem-solving for the society or the economy" [31]. In this regard, the scientific impact is frequently associated with changes in existent paradigms inducing new researching works or new schools of thought [33], although, sometimes this impact goes on beyond the academia and influence some external social environments which include economy, culture, public policy among others [34].

The types of research projects are classified in Basic Research, Applied Research, Experimental development. The soft impacts are categorized according to the dimensions of impacts of science used by the OECD [35] and adapted of [36]. Since the results obtained during all the time, show evidence that 2 group obtained results they go beyond the academy (Table 2). 
Table 2. Types of research projects.

\begin{tabular}{|c|c|c|c|c|c|c|c|c|c|c|c|c|c|c|c|c|c|c|c|c|c|c|}
\hline Projects/Years & 1999 & 2000 & 2001 & 2002 & 2003 & 2004 & 2005 & 2006 & 2007 & 2008 & 2009 & 2010 & 2011 & 2012 & 2013 & 2014 & 2015 & 2016 & 2017 & 2018 & 2019 & 2020 \\
\hline \multicolumn{23}{|l|}{ IP1 } \\
\hline \multicolumn{23}{|l|}{ IP2 } \\
\hline \multicolumn{23}{|l|}{ IP3 } \\
\hline \multicolumn{23}{|l|}{ IP4 } \\
\hline \multicolumn{23}{|c|}{ 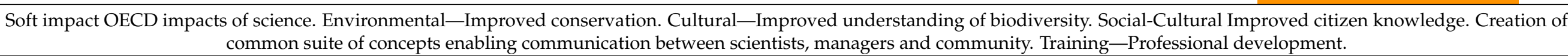 } \\
\hline \multicolumn{23}{|l|}{ IP5 } \\
\hline \multicolumn{23}{|l|}{ IP6 } \\
\hline \multicolumn{23}{|l|}{ IP7 } \\
\hline \multicolumn{23}{|l|}{ IP8 } \\
\hline \multicolumn{23}{|l|}{ IP9 } \\
\hline \multicolumn{23}{|l|}{ IP10 } \\
\hline \multicolumn{23}{|c|}{$\begin{array}{c}\text { Soft impact OECD impacts of science. Economic-Organizational. Job creation and new contract. Training-Improved graduate mobility. Social-Training- Professional development. } \\
\text { Social-Symbolic. Stronger network of professionals—industry, government, academia. }\end{array}$} \\
\hline \multicolumn{23}{|l|}{ IP11 } \\
\hline \multicolumn{23}{|l|}{ IP13 } \\
\hline \multicolumn{23}{|l|}{ IP14 } \\
\hline \multicolumn{23}{|l|}{ IP15 } \\
\hline \multicolumn{23}{|l|}{ IP16 } \\
\hline \multicolumn{23}{|l|}{ IP17 } \\
\hline \multicolumn{23}{|l|}{ IP18 } \\
\hline \multicolumn{23}{|l|}{ IP19 } \\
\hline \multicolumn{23}{|l|}{ IP20 } \\
\hline \multicolumn{23}{|l|}{ IP21 } \\
\hline IP22 & & & & & & & & & & & & & & & & & & & & & & \\
\hline IP23 & & & & & & & & & & & & & & & & & & & & & & \\
\hline IP24 & & & & & & & & & & & & & & & & & & & & & & \\
\hline IP25 & & & & & & & & & & & & & & & & & & & & & & \\
\hline IP27 & & & & & & & & & & & & & & & & & & & & & & \\
\hline
\end{tabular}


Table 2. Cont.

\begin{tabular}{|c|c|c|c|c|c|c|c|c|c|c|c|c|c|c|c|c|c|c|c|c|c|c|}
\hline Projects/Years & 1999 & 2000 & 2001 & 2002 & 2003 & 2004 & 2005 & 2006 & 2007 & 2008 & 2009 & 2010 & 2011 & 2012 & 2013 & 2014 & 2015 & 2016 & 2017 & 2018 & 2019 & 2020 \\
\hline IP26 & & & & & & & & & & & & & & & & & & & & & & \\
\hline IP28 & & & & & & & & & & & & & & & & & & & & & & \\
\hline IP29 & & & & & & & & & & & & & & & & & & & & & & \\
\hline IP30 & & & & & & & & & & & & & & & & & & & & & & \\
\hline IP31 & & & & & & & & & & & & & & & & & & & & & & \\
\hline IP32 & & & & & & & & & & & & & & & & & & & & & & \\
\hline IP33 & & & & & & & & & & & & & & & & & & & & & & \\
\hline
\end{tabular}

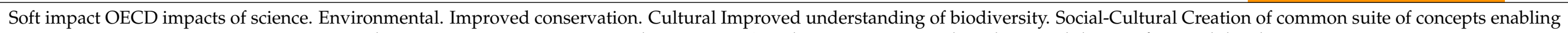
communication between scientists, managers and community Social-Training Improved graduate mobility. Professional development

Basic Research Applied Research Experimental development 
We acknowledge that generating a social impact on the investigation process it is not a linear process, which is never completed and, in many aspects, cannot be planned, ref. [36] it has been demonstrated this derived from multiple factors and it is influenced by the context where is performed. Approached from the concept of contribution instead of attribution, it is recognized that the impact in society is the result of the interaction between researchers and other interested parts and where the research is another factor more between many that influence the results $[11,12]$.

Considering the type of research, $51.51 \%$ of the projects were associated with applied research, $36.37 \%$ basic research, while $12.12 \%$ experimental development.

The technical managers who were interviewed indicated that the research had an impact on one or more of the analyzed actors.

In the case of research-to-research interactions, all projects reported results, and highlighted the organization and/or presentation in conferences, disciplinary publications, and publications in journals and books.

From research to the public sector, $57 \%$ of the projects reported results, and the most important comprised the writing of manuals and guidelines, training, and the start of thematic forums. From research to civil society, $87.88 \%$ reported results, and the most important aspect was the work with the general public, while $30.30 \%$ stated that they had research results for the public sector (Figure 7).

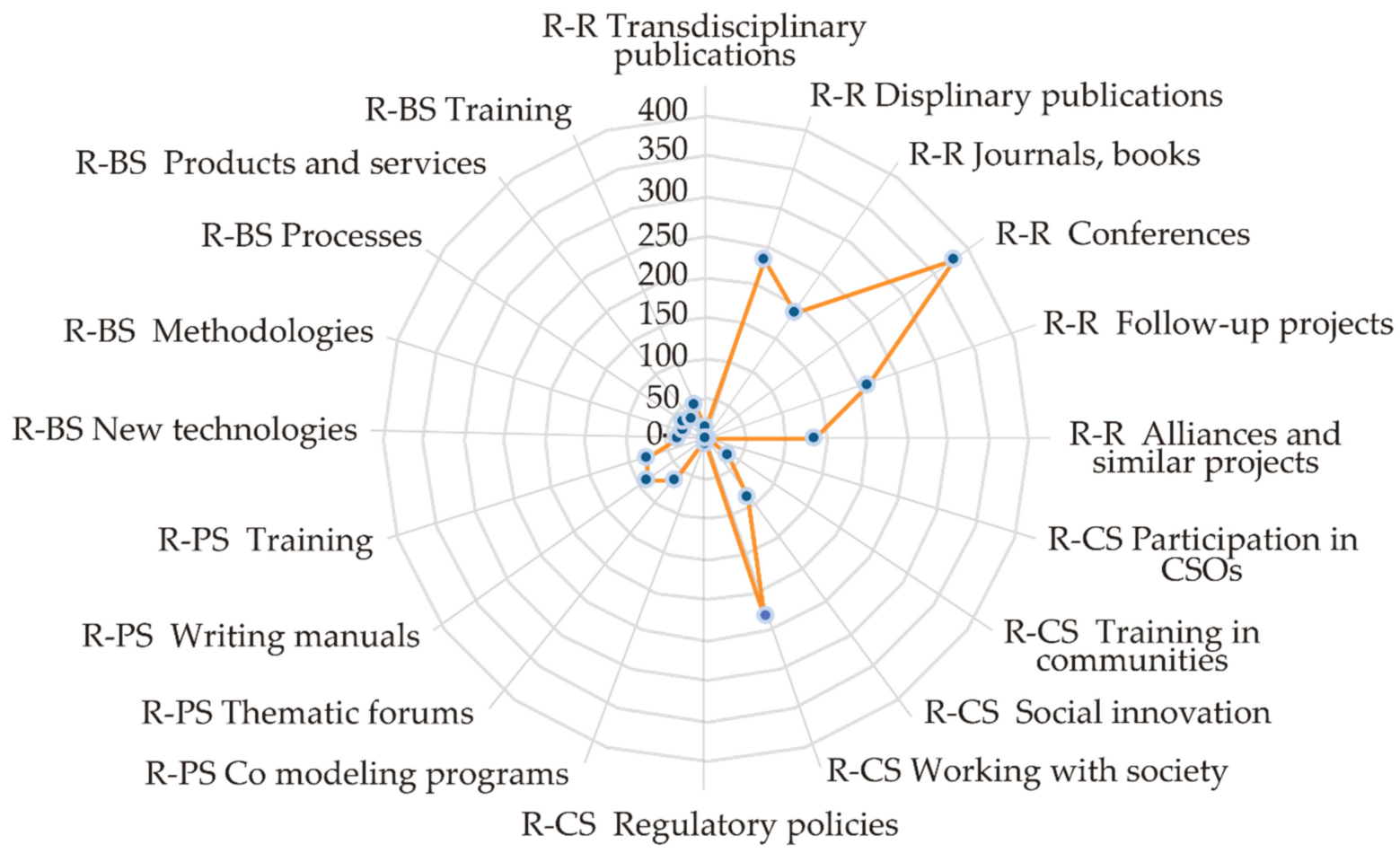

Figure 7. Results for interested parties analyzed in this study.

The technical managers who were interviewed reported the main means of sustainability being the execution of subsequent projects, either through the theses of postgraduate students or new projects, or the establishment of collaborative networks-hence, subsequent collaborations. A small number had a website on the development and achievements of the project.

\section{Discussion}

The analyzed projects are directly related to the issue of sustainability in the natural protected areas of Tamaulipas, associated in this case to the interactions that are generated for the development of research projects in these specific contexts. The research projects 
are mainly oriented on Biology issues and have generated knowledge about biodiversity, which has been published in scientific articles, books, book chapters, and conferences.

This study is a first formal assessment of the involvement of interested parties in research to create value in society and develop positive impacts in the specific social contexts of policy making, civil society, and the business sector.

Interactions between the four interested parties allow the objectives established in each project to be fulfilled. Our findings were consistent, as the interactions between the participating actors were important to determine the impact of research, because they bring together experts from different areas who have knowledge obtained empirically or not derived from scientific research. In this way, knowledge grows through this exchange and knowledge transfer [26].

The technical managers who were interviewed described the importance of the interactions but recognized that they were not included in the final project report. As a result, there are no systematic data on productive interactions with interested parties, which is consistent with what was found in the projects analyzed by the SIAMPI. The patterns and trends of the interactions showed variations that are dependent on actors. The technical managers decided on the interactions, without mediating a policy or strategy of institutional mechanisms to promote or enable the impact of the research. In the interviews conducted, there was no evidence that the institution facilitated the generation of the impact, and the funders did not ask for the incorporation of one or more actors of the quadruple helix in all cases [17].

The integration of the actors shows a tendency to strengthen the groups within the university, to meet the academic evaluation criteria. Successfully completed projects, publications produced, books edited, attendance at national and international congresses, and facilitation of student graduation, in this regard, can be considered successful.

Although universities around the world are required to exhibit and quantify the influence of their research beyond academia [36], in Mexico the public sector maintains a distant relationship to the developed projects. Some researchers participate in expert groups to address specific topics and are recognized for their expertise, but in general, this does not involve collaborative work. Researchers recognize that a closer relationship with this sector is necessary, so that the sector can understand the work they do and make decisions based on scientific evidence.

This is the opposite of the situation in most countries currently implementing several forms of impact, defined by the Organisation for Economic Cooperation and Development (OECD) as "the contribution that research makes to the economy, society, environment or culture, beyond the contribution to academic research" [35]. For instance, in the United Kingdom, the Research Excellence Framework (REF) is used to assess the impact of academic publications and prioritize projects that meet the evaluative criteria. In the Netherlands and New Zealand, research assessment is a mature process. The Netherlands is interested on the influence of research on society, and New Zealand gathers evidence of interconnections occurring beyond the academic field. Canada developed an impact framework aimed at evaluating the return of research investment in the health field. In Ireland, in 2012, the Science Foundation Ireland focused its scientific and engineering research vision on research impact assessment. In the United States, the National Science Foundation, National Institute of Health, US Department of Agriculture, and US Environmental Protection Authority developed a repository with the goal of assessing the impact of federal research. Denmark, Finland, and Israel have established impact assessment processes in their research programs. [36]. The Australian Research Quality Framework did not come to fruition [37]. On the other hand, the Times Higher Education (THE) World University Rankings adopted a new indicator of quality in institutions: The coefficient of impact and knowledge transfer.

The greatest interaction outside of the academy is with members of the community. The information obtained shows that the main beneficiaries of this interaction are the researchers, who through community members have access to expert knowledge of the 
flora and fauna of the study area. The disciplinary approach of the projects does not allow a value to be determined for this knowledge. Although in the interviews these community members indicated that they maintained a good or great relationship with the researchers, they were not given any recognition, which is demonstrated by the fact that only one researcher mentioned them by name, and none made mention of the Nagoya Protocol [38] in force since 2014. Another important consideration is that, in this sector, unlike the formal dealings with the academy, the public sector and the business sector, the relationships with community actors are essentially informal. Further study is needed to determine the value of the knowledge that researchers receive from community members, and the benefits that the community receives from researchers. Since the projects were disciplinary, it is not possible to document the interaction processes from a socio-ecological perspective. There was little interaction with civil society organizations.

The group of the business sector had considerably less interaction. The researchers reported that they were unprepared for such interactions. However, in the cases where the companies were involved, they interacted with great success and were a fundamental part of the investigation team, with a long-term relationship becoming established.

The information provided by the technical managers who were interviewed allows us to assume that the sustainability of the projects is not easy to determine. The question that arises is: How do we ensure sustainability when research is addressed as an event, not as a process? The impacts and sustainability of projects are not always evident.

A linear approach would indicate that projects developed in a short period of time do not have an apparent contribution. However, the absence of a social impact of the research does not necessarily lead directly to the idea of uselessness, but rather that conditions that support the impact processes should be considered [17]. The impact can be seen as a product, as a use of knowledge, and, finally, as social benefits that are directed to the use of the research results in different areas [8].

There is indirect evidence that the generated knowledge is used for the conservation of biodiversity in the areas of study. An analysis of the objectives, methodologies and results was performed on the 33 projects under study. Along with the information acquired from the 18 interviews with all the technical staff, the results were contrasted with the content of the existing management programs: El Cielo Biosphere Reserve (2013), Laguna Madre and Delta el Rio Bravo (2015). Results show an indirect association between the themes studied and the management program. There is evidence that the results of the research have been used in the preparation of both management programs, and $22 \%$ of the technical managers participated in their elaboration.

However, the process for the transfer of knowledge was indirect, since the public sector is responsible for coordinating the design of management programs and does not participate directly in the development of the projects but does participate in their financing. In this sense, the members of the community by having a direct participation in the development of the projects either as monitors, field guides, experts in the territory and its species, receive training, which makes the conservation of biodiversity in the natural areas studied sustainable again in an indirect way.

From the knowledge accumulation perspective, the impact can occur due to the same researcher, who can carry out a new research approach with each new project, in a new place, and in a new context, considering the knowledge accumulated in the previous project. In the analysis by group of projects developed by the same researcher, it was expected that the researcher develops each new project with greater knowledge, and incorporates the results obtained in previous projects.

The patterns and trends show a strong tendency to associate with members of the same research sector, from the same institution, and the participation of the same person in different projects. This limits the impact potential of projects through productive interactions. Overall, there was a significant difference in the level, intensity, mode, and time of the interactions with other interested parties. These depend on the amount of funding, project type and duration, and, perhaps most significantly, on the profile of the 
technical manager. On the one hand, we identified 13 different fields of knowledge that encompassed the 33 analyzed projects, which indicates a wide range of areas of study. On the other hand, $51 \%$ of the projects addressed topics that were not studied afterwards. This means that the analyzed research was divergent and discontinuous.

\section{Limitations}

The orientation of this study was to highlight the concentration of impacts and the gap that exists to achieve social impact that other countries such as the United Kingdom, New Zealand, or the Netherlands or Canada have reached through clear policies to conduct to research projects with impact.

Our intention was twofold. First, to compare the interactions and the performance of the researchers in the projects. Second, to demonstrate that the impacts remain at the level of academia.

The study was carried out utilizing a qualitative methodology. Therefore, the results obtained cannot be generalized to other projects, and are only applicable to the projects analyzed and that were executed in the Protected Natural Areas of Tamaulipas. Although the institutional conditions are the same for other projects, these will be affected by the specific characteristics of the technical managers and the specific contexts from which they are developed.

Although this research identified the interactions and their contexts in general, the intention was to move beyond just counting them to identifying their impact $[17,21]$. We recognize that a possible way to search for impact is the management and promotion of interactions' productive activities, that under certain conditions can generate social impact $[4,8,12,32]$.

It was assumed that the self-assessments conducted by the technical managers who were interviewed may not be objective and may tend to have a positive bias. It is recognized that the analysis may not be representative because it was based on projects conducted by researchers from the Autonomous University of Tamaulipas that received internal or external funding. Moreover, some projects may have been conducted with the researcher's own resources, which was not considered in this study.

Complete analyses of all projects were conducted, which supported a preliminary establishment of some patterns and mechanisms regarding the types of interactions between researchers, the public sector, civil society, and the private sector, and their possible impacts. A similar study will be carried out for projects developed by researchers in different areas of knowledge at the Autonomous University of Tamaulipas in future.

Author Contributions: Conceptualization, F.C.C.-R.; methodology, F.C.C.-R. and J.A.R.d.L.; software, R.V.R.H. and D.A.G.-B.; validation, B.L.D.M.; formal analysis, F.C.C.-R. and B.L.D.M.; investigation, F.C.C.-R. and B.L.D.M.; resources, F.C.C.-R. and B.L.D.M.; data curation, R.V.R.H. and D.A.G.-B.; writing—original draft preparation, F.C.C.-R.; writing—review and editing, F.C.C.-R., R.V.R.H.; visualization, J.A.R.d.L., D.A.G.-B.; supervision, J.A.R.d.L.; project administration, F.C.C.-R.; funding acquisition, F.C.C.-R. and B.L.D.M. All authors have read and agreed to the published version of the manuscript.

Funding: This research received no external funding.

Institutional Review Board Statement: Not Applicable.

Informed Consent Statement: Not Applicable.

Data Availability Statement: The data presented in this study are available on request from the corresponding author.

Acknowledgments: We are grateful for the support provided by the researchers we interviewed, who made this research possible, and to the Autonomous University of Tamaulipas for the financial support for the publication of the article.

Conflicts of Interest: The authors declare no conflict of interest. 


\section{References}

1. Ozanne, J.L.; Davis, B.; Murray, J.B.; Grier, S.A.; Benmecheddal, A.; Downey, H.; Ekpo, A.E.; Garnier, M.; Hietanen, J.; Le Gall-Ely, M.; et al. Assessing the Societal Impact of Research: The Relational Engagement Approach. J. Public Policy Mark. 2017, $36,1-14$. [CrossRef]

2. Wiek, A.; Talwar, S.; O'Shea, M.; Robinson, J. Toward a methodological scheme for capturing societal effects of participatory sustainability research. Res. Eval. 2014, 23, 117-132. [CrossRef]

3. Pinar, M.; Unlu, E. Determinants of quality of research environment: An assessment of the environment submissions in the UK's Research Excellence Framework in 2014. Res. Eval. 2020, 29, 231-244. [CrossRef]

4. Spaapen, J.; Sivertsen, G. Assessing societal impact of SSH in an engaging world: Focus on productive interaction, creative pathways and enhanced visibility of SSH research. Res. Eval. 2020, 29, 1-3. [CrossRef]

5. McCann, P.; Ortega-Argilés, R. Modern regional innovation policy. Camb. J. Reg. Econ. Soc. 2013, 6, 187-216. [CrossRef]

6. Murray, J.B.; Ozanne, J.L. The critical participant. J. Mark. Manag. 2009, 25, 835-841. [CrossRef]

7. Joly, P.-B.; Matt, M. Towards a new generation of research impact assessment approaches. J. Technol. Transf. 2017, 1-11. [CrossRef]

8. Bornmann, L. What is societal impact of research and how can it be assessed? A literature survey. J. Am. Soc. Inf. Sci. Technol. 2012, 64, 217-233. [CrossRef]

9. De Jong, S.; Barker, K.; Cox, D.; Sveinsdottir, T.; Besselaar, P.V.D. Understanding societal impact through productive interactions: ICT research as a case. Res. Eval. 2014, 23, 89-102. [CrossRef]

10. De Jong, S.P.; Van Arensbergen, P.; Daemen, F.; Van Der Meulen, B.; Besselaar, P.V.D. Evaluation of research in context: An approach and two cases. Res. Eval. 2011, 20, 61-72. [CrossRef]

11. Morton, S. Progressing research impact assessment: A 'contributions' approach. Res. Eval. 2015, 24, 405-419. [CrossRef]

12. Spaapen, J.; Van Drooge, L. Introducing 'productive interactions' in social impact assessment. Res. Eval. 2011, 20, 211-218. [CrossRef]

13. Rymer, L. Measuring the Impact of Research: The Context for Metric Development. Available online: https: / / eric.ed.gov/?id= ED536201 (accessed on 30 September 2011).

14. Van Drooge, L.; Spaapen, J. Evaluation and monitoring of transdisciplinary collaborations. J. Technol. Transf. 2017, 1-15. [CrossRef]

15. Boshoff, N.; Sefatsa, M. Creating research impact through the productive interactions of an individual: An example from South African research on maritime piracy. Res. Eval. 2019, 28, 145-157. [CrossRef]

16. Benneworth, P.S.; Gulbrandsen, M.; Hazelkorn, E. The Impact and Future of Arts and Humanities Research; Palgrave Macmillan; Springer Nature: London, UK, 2016.

17. Muhonen, R.; Benneworth, P.; Olmos-Peñuela, J. From productive interactions to impact pathways: Understanding the key dimensions in developing SSH research societal impact. Res. Eval. 2019, 29, 34-47. [CrossRef]

18. Van den Akker, W.; Spaapen, J. Productive interactions: Societal impact of academic research in the knowledge society. LERU Position Pap. 2017, 31, 49.

19. Van Drooge, L.; Vandeberg, R. Valuable-understanding valorisation. In Proceedings of the 2013 Eu-SPRI Forum Conference, Management of Innovation Policies, Madrid, Spain, 10-12 April 2013.

20. Morton, S. Creating research impact: The roles of research users in interactive research mobilisation. Evid. Policy J. Res. Debate Pr. 2015, 11, 35-55. [CrossRef]

21. Benneworth, P.S.; Olmos-Peñuela, J. Reflecting on the Tensions of Research Utilization: Understanding the Coupling of Academic and User Knowledge. Sci. Public Policy 2018, 45, 764-774. [CrossRef]

22. Ostrom, E.; Ahn, T.K. Una perspectiva del capital social desde las ciencias sociales: Capital social y acción colectiva. Rev. Mex. Sociol. 2003, 65, 155-233. [CrossRef]

23. Ostrom, E. Beyond Markets and States: Polycentric Governance of Complex Economic Systems. Am. Econ. Rev. 2010, 100, 641-672. [CrossRef]

24. Annemans, M.; Heylighen, A. Productive interactions to exchange knowledge in healthcare building design. Build. Res. Inf. 2020, 1-13. [CrossRef]

25. Kafouros, M.; Love, J.H.; Ganotakis, P.; Konara, P. Experience in R\&D collaborations, innovative performance and the moderating effect of different dimensions of absorptive capacity. Technol. Forecast. Soc. Chang. 2020, 150, 119757. [CrossRef]

26. Mao, C.; Yu, X.; Zhou, Q.; Harms, R.; Fang, G. Knowledge growth in university-industry innovation networks-Results from a simulation study. Technol. Forecast. Soc. Chang. 2020, 151, 119746. [CrossRef]

27. Whitley, R. The Intellectual and Social Organization of the Sciences; Oxford Univesity Press: Oxford, UK, 2000.

28. Molas-Gallart, J.; Tang, P. Tracing 'productive interactions' to identify social impacts: An example from the social sciences. Res. Eval. 2011, 20, 219-226. [CrossRef]

29. Godin, B.; Doré, C. Measuring the Impacts of Science: Beyond the Economic Dimension; HIST Lecture: Quebec, QC, Canada, 2005; pp. $1-44$.

30. Bell, S.L.; Shaw, B.; Boaz, A. Real-world approaches to assessing the impact of environmental research on policy. Res. Eval. 2011, 20, 227-237. [CrossRef]

31. Carayannis, E.G.; Campbell, D.F. Triple Helix, Quadruple Helix and Quintuple Helix and How Do Knowledge, Innovation and the Environment Relate to Each Other? Int. J. Soc. Ecol. Sustain. Dev. 2010, 1, 41-69. [CrossRef] 
32. Baber, Z.; Gibbons, M.; Limoges, C.; Nowotny, H.; Schwartzman, S.; Scott, P.; Trow, M. The New Production of Knowledge: The Dynamics of Science and Research in Contemporary Societies. Contemp. Sociol. J. Rev. 1995, 24, 751. [CrossRef]

33. Reale, E.; Avramov, D.; Canhial, K.; Donovan, C.; Flecha, R.; Holm, P.; Larkin, C.; Lepori, B.; Mosoni-Fried, J.; Oliver, E.; et al. A review of literature on evaluating the scientific, social and political impact of social sciences and humanities research. Res. Eval. 2018, 27, 298-308. [CrossRef]

34. Penfield, T.; Baker, M.J.; Scoble, R.; Wykes, M.C. Assessment, evaluations, and definitions of research impact: A review. Res. Eval. 2014, 23, 21-32. [CrossRef]

35. OECD 2010. Enhancing Public Research Performance through Evaluation, Impact Assessment and Priority Setting; OECD: Paris, France, 2010; pp. 1-164.

36. Fryirs, K.A.; Brierley, G.; Dixon, T.A. Engaging with research impact assessment for an environmental science case study. Nat. Commun. 2019, 10, 4542. [CrossRef]

37. Donovan, C. The Australian Research Quality Framework: A live experiment in capturing the social, economic, environmental, and cultural returns of publicly funded research. New Dir. Eval. 2008, 2008, 47-60. [CrossRef]

38. Buck, M.; Hamilton, C. The Nagoya Protocol on Access to Genetic Resources and the Fair and Equitable Sharing of Benefits Arising from their Utilization to the Convention on Biological Diversity. Rev. Eur. Community Int. Environ. Law 2011, 20 , 47-61. [CrossRef] 